\title{
Reframing Design under Technical Conditions
}

\author{
Moritz Greiner-Petter and Claudia Mareis \\ Institute of Research in Art and Design, Basel, Switzerland \\ \{moritz.greinerpetter, claudia.mareis\} afhnw.ch
}

\begin{abstract}
In recent years concepts and approaches of scientific epistemology and sociology of science have been applied to the field of design and thereby considerably exposed the epistemological qualities and socio-material configurations in the practice of designing. However, technical paradigms and characteristics of design practice as a specific form of technical activity have been slightly neglected. In considering positions from the philosophy and sociology of technology as well as media theory, we attempt to resume promising approaches that move in this direction and indicate what the implications of such approaches might be for creative practices. By elaborating these aspects, we aim to reframe contemporary design cultures and practices within technical conditions.
\end{abstract}

Keywords: Design Theory, Design Philosophy, Epistemology, Technical Cultures in Design, Science and Technology Studies (STS), Tools, Software.

\section{Introduction}

In this paper, we want to gain a deeper understanding of technically driven design cultures and practices. This we aim to do by elaborating and differentiating the role of technical objects within design processes. In a more general view, we are interested in an up-dated notion of the technical respectively techné within contemporary design cultures and practices, especially in the realm of digital media practices and interaction design.

Over the past few years, design has been increasingly discussed within the framework of scientific epistemology as well as from the perspective of Science and Technology Studies (STS). Thus, the epistemological qualities of design cultures and practices, their potential in the production of new knowledge have been widely researched and discussed in-depth. Scholars from both STS, and design, artistic, and architectural research fields have been investigating architectural practices [1,2] design cultures and techniques [3,4], as well as the epistemic role of models [5], sketches, or drawings [6,7]. Special attention has been given here to the visual and material dimensions of designing, especially to the notion of "objects" and "things" [8,9]. Slightly less attention however has been given to the aspects of tools and instruments, as well as to technical paradigms of designing. 
Design always has been and is increasingly becoming a discipline bound to technological domains. It is vital in designing to exploit the potentialities of production techniques in creative ways and to expand its means of creation through technological research. That way, it also reshapes its very scope of application by exploring new design spaces along technological advancement in general. In that sense, complex tools like computers and especially software constitute a significant background for contemporary design practices to unfold. We consider it important to foster a critique of digital media regarding its stake in structuring creative practices, shaping aesthetics of production and establishing conceptual and discourse paradigms in design.

\section{Technical Objects}

The growing theoretical interest in design as a knowledge-intensive discipline draws from previous work in social studies of science and technology and those studies' research into the epistemological status of material relations, artifacts and representations within creative practices. The conceptualization of "epistemic objects" and "technical objects" by historian of science Hans-Jörg Rheinberger [10] has been an especially fruitful resource for analysis of knowledge production embedded in material environments beyond scientific domains. Ewenstein and Whyte [11] have recently differentiated these kinds of objects and how they come into use in architectural practice. Drawing on Rheinberger, they distinguish between "technical objects," "epistemic objects," and "boundary objects". While technical objects are described as "taken-for-granted" [11, p.9], "fixed and stable tools" that are "ready-tohand, complete and unproblematic instruments," epistemic objects are characterized in a more dynamic, somewhat fuzzy way by their "lack and incompleteness," "partially expressed in multiple instantiations," "continuously evolving" [11, p.10]. On the contrary, the concept of "boundary objects," first described by Star [12] and Star/Griesemer [13], is described as being less material, more discursive and interactive: as an "object that is differently interpreted and provides a holding ground for ideas for communication, translation and standardization of meaning" [11, p.10].

While the concepts of both epistemic and boundary objects have been discussed thoroughly, the description of technical objects appears to lack more detailed elaboration. This observation seems to be accompanied by or is even based on a rather indifferent, out-dated notion of the technical and techné within the analysis of contemporary design. Looking at design cultures and practices through the lens of epistemology has certainly led to a better understanding of design. However, due to the subsuming and subordination of technical aspects under the auspices of epistemic (mostly scientific) concepts, a somewhat shortened, indifferent understanding of design now seems to dominate the discourse - in terms of knowledge production and innovation processes. 


\section{Problematizing Technical Objects}

The understanding of technical objects as stable and unproblematic tools, merely as taken-for-granted instruments, might become questionable in the context of the technical transformation of creative settings. When conceptualizing the technical equipment in which practices are embedded simply as a means to an end, the productivity of their specific mediality is underestimated. The materiality and structure of technical media always create a deficit as well as a surplus of meaning and expressive qualities that are beyond the explicit control of the user [14].

In a similar notion, Don Ihde turns the attention in his philosophical analysis of technology not only to common aspects of amplification and enhancement but also to their potential in reducing spaces of perception [15]. As he puts it, "for every revealing transformation there is a simultaneously concealing transformation of the world, which is given through a technological mediation. Technologies transform experience, however subtly, and that is one root of their non-neutrality" [15, p.49]. Referring to optical technologies like the microscope and telescope, Ihde highlights the transformation of perceptions through technological instrumentation: As a such instruments reveal previously unknown phenomena with magnification, bringing them closer and focally into the center of vision, the instruments simultaneously reduce an observer's sense of depth and the size and location of the objects in their context [15, p.50]. The technological mediation is transforming the very sense of bodily and world space as it were, diminishing the foreground in magnifying what lies in the background of perception.

Comparable to Ihde, Albert Borgmann argues in his philosophy of technology against supposedly dominating promises of liberation and enrichment concerning modern technologies [16]. Beyond perceptual transformations, Borgmann focuses on the displacement of practices and social dimensions connected to technological progress. Referring to Martin Heidegger, he develops the distinction between "things" and "devices" in his analysis. According to him, "things" are traditional technological configurations that constitute complex practices around themselves. They are highly contextual, unfold focusing and centering qualities, thus serve as orienting experiences that demand manifold bodily and social engagement [16, p.41]. As they incorporate means and ends inseparably, they convey a sense of depth and integrity [17, p.210]. Modern technologies seek to subvert these focal practices and reconstitute "things" as "devices." This way, they reduce the complex qualities of the original "thing" that they have achieved in replacing with a mere commodity, narrowed to a limited purpose. Transformed in an instantaneous, available, safe, and easy technology [16, p.41], they are detached from a definite context, exhibiting a distinction of means and ends [16, p.43]. Their commodious character renders "devices" as being less demanding, less engaging, shallow experiences [17, p.206]. Borgmann exemplifies this "device paradigm" with the central heating plant, which technologically has transformed the fireplace into a device to merely provide warmth as a commodity, and as such the social and cultural dimensions of the practices of work, skill, knowledge, and sociality surrounding the traditional stove are diminished $[16, \mathrm{p} .42]$. 
Although debatable in their implications, the two techno-critical standpoints outlined above serve to broaden the perspective on technical objects and question a notion of them as unproblematic tools. Drawing from Ihde and Borgmann in the context of creative practices, the question can be raised: How does the technical transformation of tools involved in designing also alter the space for expression and the very condition for creativity? Similar to the argument for optical technologies, it can be argued that the use of information technology and communication media influences the relationship between sense and skill and conceptions of time and space. As Ihde also points out, technical instrumentation has transformed and is transforming the contexts within which disciplines produce knowledge or artifacts and are understood, be it science or artistic and designerly practices [15, p.187], as they settle new spaces of experience or objectifications of sense. By enabling distinct modes of creation and framing specific production aesthetics in design, the technical ensembles might become problematic regarding their productive agency. Put differently, the qualities and intricate structure of knowledge-intensive creative practices might reflect the modalities of the tools and equipment that assist in composing design work. These questions gain relevance especially in contemporary design culture, where a majority of activity in practice is mediated by digital technologies - from research, inspiration, and visualization to creation, generation, and production. The intensity and dynamic of these interactions makes up the ambiguity of technical objects that, we argue, needs to be refined to further comprehend creative practices.

\section{An Updated Notion of "The Technical"}

Thinking about technical conditions in contemporary design practices more specifically beyond the realms of philosophy of technology could address not only but at least two levels of consideration. On the one hand, the instrumental notion of the tool needs to be expanded in order to grasp the processual dimension of technical activity embedded in a complex and distributed configuration. On the other hand, in a movement connected to that but facing the opposite direction, particular modalities and structures within specific technical elements and the effects arising from them need to be considered.

Technology has long been conceptualized in an exteriority or an organic extension of its user in a relationship described in categories of purposefulness, utility, and instrumentality $[18,19]$. In terms of the history of ideas, it was mainly conceived in a manner of distinction or opposition, be it from nature, culture, or society [19]. The development of the technological condition of today, namely an expansive media-technological pervasion, has provoked a theoretical sensibility for the transinstrumental, non-intentional, distributed, and processual characters of humanmachine-relations. Already the ancient notion of the technical or techné comprised an ensemble of things, actors, and activities in which technical actions are embedded and constituted [20]. It could articulate technical activity in a processual manner, implicating a form of social activity [19, p.42]. That notion has been updated and elaborated in the last decades not only but most prominently at the hands of the Actor 
Network Theory, which posits an ontological symmetry of human and non-human actors [19, p.40]. That way, technical activity in contemporary technological conditions became graspable in terms of situated hybrids of human-machine interactions and agency - the capacity for action - as temporally emergent phenomena, distributed across a social and material field of actants. Tools in that sense expand far beyond a particular material instrument that can be conceptualized as a single object outside of and opposite to its user. The boundaries of the conception of a tool become rather ambiguous, incorporating a mesh of practices that exhibit operative behavior. Technical activity then is the effect of a movement along the human-machine-boundary, between objectification and subjectification, where technologies can become actors in the same way as human practices can become methods or commodities [21]. Along these lines, while the inseparable and mutually constituting human-machine relationships must be recognized, particular accountabilites [21] or degrees of distribution [19] of agency can be located nevertheless. This understanding of a Heideggerian "equipmental whole" [20] in the context of design practices is more interested in the processual and emergent dimension and relationships of dependence of the technical embeddedness than its instrumental character. It is apt to make graspable, how the economy of associations, aesthetic negotiations, and creative agency is distributed throughout production environments and could be mapped out and rendered visible. The technical then encompasses the interplay of embodied as well as externalized, mediated, communicative, and social qualities that constitute the activity of designing.

At the same time, complex apparatuses like computational tools can themselves be viewed as assemblages of different concepts, functions, and structures. This way, approaching the transformation of creative settings on the level of specific technological manifestations and unfolding their particular characteristics can be a strategy to gain understanding of design under technical conditions. Both Matthew Fuller with his "software criticism" [22] and Lev Manovich in his attempt to establish a "software studies" [23] argue for an "unfolding of particularities" [22] in the workings of digital media tools in order to understand their involvement in transforming aesthetic cultures or shaping conceptual models of creative practices. In analyzing common media content production software in terms of interface metaphors, the working of commands, and surrounding workflows, Manovich tries to reveal how they invoke critical displacements on all kinds of levels [24,23]. Instancing digital video compositing software, he points out how certain software paradigms enabled the emergence of new visual languages and logics of form. Foremost, the integration of traditionally separated media forms in digital software lead to new media hybrids that exhibit deep remixability. Pre-digital media operations that are now rendered with computer software change in their inner logic and functioning as they get digitally augmented and parameterized. Conceptual metaphors provided by these tools like layers, transparency, and compositing tend to change the designer's or artist's understanding of what a moving image is, how to think about it and how to design it. He underlines that in mentioning how the idea of animated form enters architectural thinking via concepts established in video compositing software, which finally results in computational and generative aesthetics in architecture that 
differ from traditional designing based on spatial typologies, for instance. Due to the widespread availability of and the unification of media forms by software, Manovich argues furthermore that professional boundaries between different fields of design have become less important. In considering software tools from the bottom up, looking at particular interface elements and functions, an approach like Manovich's tries to expose the traces of technicality to be found in mental models of designers, everyday workflow structures up to media cultures and aesthetic languages within a field of practice.

Both levels of consideration outlined above are complementary or transitional and lie on a spectrum of possible entry points into an understanding of the technicality of a practice like that of design. Specific materialities, constraints and possibilities of particular (digital) tools afford skillful or instrumental, non-intentional, automatized or routinized, messy or improvisational engagements which entangle intricate ways of socio-material relations and activities, mobilize and coordinate forms of knowledge, communications or imaginations, which also applies the other way around for each of these.

\section{Design as a Technical Activity}

Some of the implications of transferring the outlined positions from philosophy, sociology, and the aesthetics of technology to design practices were already implied and need to be elaborated in the future. In conclusion, we want to put forth possible interpretations concerning the aspect of creativity in computationally transformed creative settings.

The cultivation of creativity is a central concern of design practices, which seek to facilitate contextual innovation in a more or less systematic or methodological manner. Facilitating creativity has long been connected to efforts of systematization and cognitive techniques [3]. In contemporary technology-saturated work contexts, creativity, artistic expressiveness, and virtuosity are for great parts realized within software environments. With Ihde and Borgmann the techno-logical effects of amplification and reduction came into view. The technologization of processes and their specific mediality opens up spaces for expression and innovation, while diminishing others at the same time. An ambivalence regarding technicality in designing arises from the efforts to technologically implement and translate qualities like creative intention, skills, and practical knowing that might be all at once hard to systematize and to articulate. From the perspective of Manovich, the design of the computational tools involved becomes problematic as it can effect crucial aspects of practice and workflow - from the conceptual models of media and content that are established to the amount of structure imposed on the work or process, the kinds and qualities of representations, the levels of abstraction necessary, the kinds of manipulations implemented to the openness, and extensibility of the tool [25]. In a wider context of distributed agency, it can be asked then: How is the accountability for creativity, aesthetic judgments and design decisions socio-materially negotiated and coordinated and spread across the equipmental whole. The advances in generative 
and parameterized design, for instance, could be seen as forms of co-creation and authoring with algorithms that enable and demand the designer to react to the logic of forms and aesthetics rendered by the computational tools in changing degrees.

Furthermore, the specific materialities of computing have also become a place for design exploration itself. Fields like interaction design and new media design explicitly investigate the idiosyncratic expressive potentials of computational media and the interface between humans and computers. Systemic properties like interactivity, generativity, computational complexity, networked behavior, and emergence become categories for designing and get part of the palette of expressive materials to work with. These computational possibilities also seem to open up the design space for practitioners for whom coding and programming techniques are ever more often becoming part of their technical and conceptual repertoire.

\section{Conclusions}

While several fields of designerly as well as artistic practice have been analyzed quite intensively in the context of epistemology and new knowledge production introduced in recent years, in this paper we wanted to shift the focus to their technical condition of possibility. We put forth some promising reflections in order to look at contemporary practices in design from the perspective of their technicality. According to our view, the technical instruments themselves still remain somewhat marginalized in the analysis of creative practices, especially considering digital media tools.

With the notions presented here, we wanted to propose some of the possible coordinates for a refinement in the analysis of contemporary design practices with an emphasis on its technical conditions. Further research is needed to better understand the ways in which tools are structuring and mediating creative practices. This could lead to insights not only into the nature of contemporary design activities but also enhancements in knowledge for designing digital tools that support creative work. Furthermore, considering a pervasiveness of practices of programming in fields like digital media design and interaction design, the adoption of coding practices and the interference with technical paradigms from realms outside design need further exploration. As technologies tend to withdraw, to be perceived as ready-to-hand tools and embedded in other qualities of practices, specific modes of researching their interactions and transformations require elaboration as well. To make creative practices like designing more comprehensible, the complex interplay of actors within technical ensembles as well as material and knowledge practices needs to be uncovered further. This aims at strengthening a position of research that approaches design practices as an intricate interplay of knowledge, technologies, and actions.

\section{References}

1. Yaneva, A.: The making of a building: a pragmatist approach to architecture. Peter Lang, Oxford (2009)

2. Ammon, S., Froschauer, E.M. (eds.): Wissenschaft entwerfen: vom forschenden Entwerfen zur Entwurfsforschung der Architektur. Fink, München (2013) 
3. Mareis, C.: Design als Wissenskultur: Interferenzen zwischen Design- und Wissensdiskursen seit 1960. Transcript, Bielefeld (2011)

4. Gethmann, D., Hauser, S. (eds.): Kulturtechnik Entwerfen: Praktiken, Konzepte und Medien in Architektur und Design Science. Transcript, Bielefeld (2009)

5. Wendler, R.: Das Modell zwischen Kunst und Wissenschaft. Fink, München (2013)

6. Latour, B.: Drawing Things Together. In: Lynch, M., Woolgar, S. (eds.) Representation in Scientific Practice, pp. 19-68. MIT Press, Cambridge (1990)

7. Wittmann, B.: Papierprojekte. Die Zeichnung als Instrument des Entwurfs. Z. Für Medien. Kult. 2012, pp. 123-138 (2012).

8. Latour, B.: A Cautious Prometheus? A Few Steps Toward a Philosophy of Design (With Special Attention to Peter Sloterdijk). In: Hackne, F., Glynne, J., Minton, V. (eds.) Proceedings of the 2008 Annual International Conference of the Design History Society, pp. 2-10. Universal Publishers, Falmouth (2009)

9. Ehn, P.: Participation in design things. In: Proceedings of the Tenth Anniversary Conference on Participatory Design, pp. 92-101. Indiana University, Indianapolis (2008)

10. Rheinberger, H.-J.: Toward a history of epistemic things: synthesizing proteins in the test tube. Stanford University Press, Stanford (1997)

11. Ewenstein, B., Whyte, J.: Knowledge Practices in Design: The Role of Visual Representations as 'Epistemic Objects'. Organ. Stud. 30, 7-30 (2009)

12. Star, S.L.: The structure of ill-structured solutions: boundary objects and heterogeneous distributed problem solving. In: Gasser, L.G., Huhns, M.N. (eds.) Distributed Artificial Intelligence, vol. 2. Pitman, London (1989)

13. Star, S.L., Griesemer, J.R.: Institutional Ecology, 'Translations' and Boundary Objects: Amateurs and Professionals in Berkeley's Museum of Vertebrate Zoology, 1907-39. Soc. Stud. Sci. 19, 387-420 (1989)

14. Krämer, S.: Das Medium als Spur und als Apparat. In: Krämer, S. (ed.) Medien, Computer, Realität. Wirklichkeitsvorstellungen und Neue Medien, pp. 73-94. Suhrkamp, Frankfurt am Main (1998)

15. Ihde, D.: Technology and the lifeworld: from garden to earth. Indiana University Press, Bloomington (1990)

16. Borgmann, A.: Technology and the character of contemporary life: a philosophical inquiry. University of Chicago Press, Chicago (1987)

17. Borgmann, A.: Focal Things and Practices. In: Dreyfus, H.L., Wrathall, M.A. (eds.) Heidegger Reexamined, pp. 194-210. Routledge, New York (2002)

18. Hörl, E. (ed.): Die technologische Bedingung: Beiträge zur Beschreibung der technischen Welt. Suhrkamp, Berlin (2011)

19. Rammert, W.: Technik - Handeln - Wissen: zu einer pragmatistischen Technik- und Sozialtheorie. VS Verlag für Sozialwissenschaften, Wiesbaden (2007)

20. Uhlig, F.: Robinsons Pflug. Werkzeuge zwischen Nachbau und Erfindung. In: Schmitz, T.H., Grohninger, H. (eds.) Werkzeug-Denkzeug: manuelle Intelligenz und Transmedialität kreativer Prozesse, pp. 165-190. Transcript, Bielefeld (2012)

21. Suchman, L.A.: Human-machine reconfigurations: plans and situated actions. Cambridge University Press, Cambridge (2007)

22. Fuller, M.: Behind the blip: Software as culture. Nettime Mail. List. 7 (2002)

23. Manovich, L.: Software takes command: extending the language of new media. Bloomsbury, New York (2013)

24. Manovich, L.: Inside Photoshop. Comput. Cult. 1 (2011)

25. National Research Council (U.S.): Beyond productivity: information technology, innovation, and creativity. National Academies Press, Washington, DC (2003) 